\title{
GEOMORPHOLOGICAL STUDY OF KLEINOVITIKOS STREAM DRAINAGE NETWORK (TRIKALA PREFECTURE - WESTERN THESSALY)
}

\author{
Bathrellos G. D. ${ }^{1}$, Skilodimou H. D. ${ }^{1}$, Livaditis G. ${ }^{1}$, and Verikiou- \\ Papaspiridakou E. ${ }^{1}$
}

${ }^{1}$ National and Kapodistrian University of Athens, Faculty of Geology and Geoenvironment,
Department of Geography - Climatology,gbathrellos@geol.uoa.gr,hskilodimou@euof.uoa.gr

\begin{abstract}
The Kleinovitikos stream is a tributary of Pineios River in the Western Thessaly. Its basin drainages parts of mountain range of Southern Pindos as well as the mountain of Kozlaka. In this study a quantitative analysis of drainage network was accomplished and the relation of tectonics features with the watershed and the channels of drainage network were investigated.

The main channel of the drainage network is of $6^{\text {th }}$ order, while the dominated type of the network is the trellis drainage pattern. The morphological slopes of the basin show various fluctuations. The gentle slopes express erosional landforms while the steep ones represent geological and tectonic structures.

It was noted by the quantitative analysis of the drainage network that the geological and tectonic structure of the area affects in its evolution. Moreover, the outcrop of heterogeneous lithological formations in the basin affects the values of drainage density and frequency.

The lithology and the secondary cracks involve in the prevailing direction of the watershed. The streams of $1^{\text {st }}-3^{\text {rd }}$ order are controlled by the younger cracks; the younger cracks as well as the older Alpine cracks have an influence on the streams of $4^{\text {th }}$ and $5^{\text {th }}$ order, and the Alpine tectonic activity affects the stream of $6^{\text {th }}$ order.
\end{abstract}

Key words: streams, slope, lithology, tectonic features.

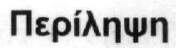

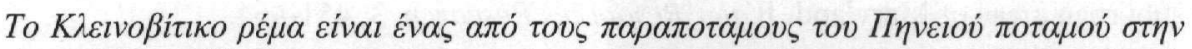

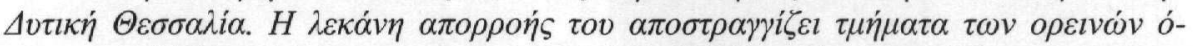

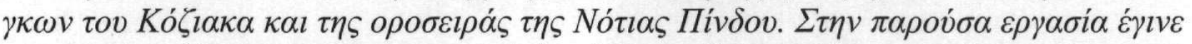

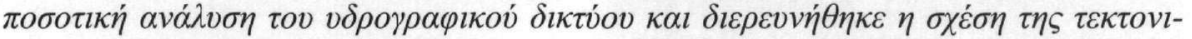

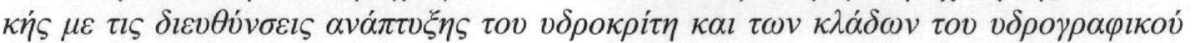

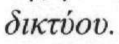

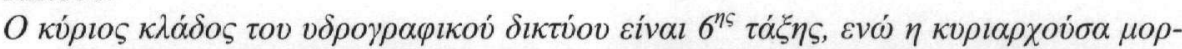

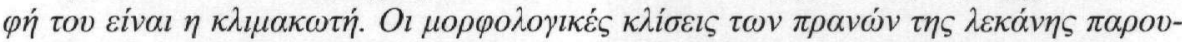

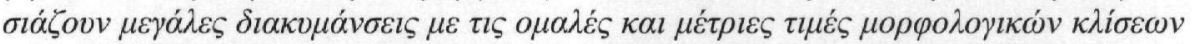

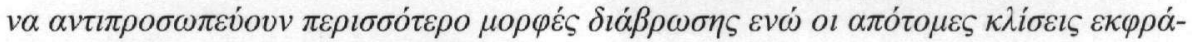

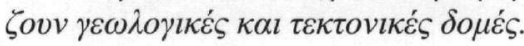




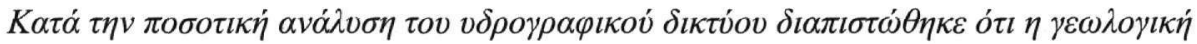

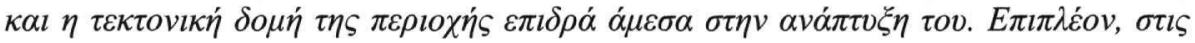

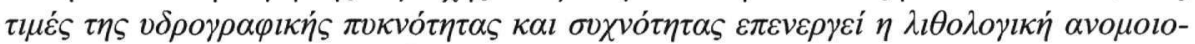

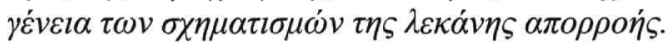

$\Sigma \tau \eta v$

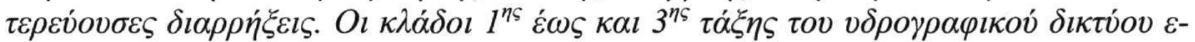

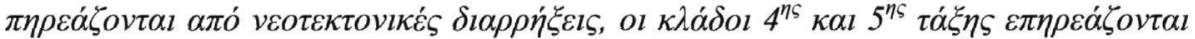

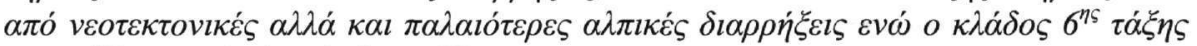
$\varepsilon \pi \eta \rho \varepsilon \dot{\zeta} \zeta \tau \tau \alpha l \alpha \pi \dot{\alpha} \alpha \lambda \pi \imath \kappa \varepsilon \dot{\zeta} \delta \imath \alpha \rho \rho \dot{\eta} \xi \varepsilon l \zeta$.

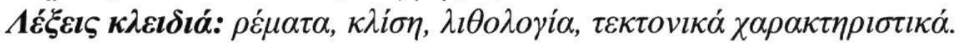

\section{Introduction}

The Kleinovitikos stream is one of the tributaries of Pineios River in the region of basin of Western Thessaly. Its drainage basin, as appears in the figure 1, is found in the central part of Trikala prefecture. The Kleinovitikos stream drains parts of the mountain range of Southern Pindos as well as the mountain of Koztakas. Its drainage divide follows the crests of ridges of the mountains.

The Kleinovitikos stream flows from northeast to southwest and it is shaped by the joining of six streams. Moreover, the streams, which contribute in this, are the following: Valamazi, Vrysi, Katounitsa, Mantania, Pigeon and Houtianas. The main channel of Kleinovitikos stream before his contribution with Pineios River becomes a brained stream. This is an effect of maldistribution of water flow during the year.

In this study a quantitative analysis of the drainage network of Kleinovitikos stream was accomplished and its morphometric parameters were studied aiming at the localization of factors that affected in its evolution. Moreover, the relation of tectonics of the surrounding study

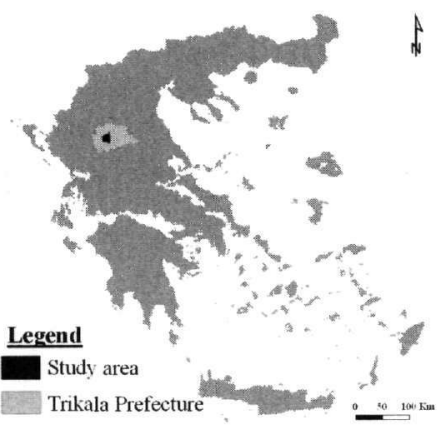

Figure 1 - The studv area area with the orientation of watershed and the channels of drainage network was investigated. For this reason a statistical analysis and comparison of the orientation and length direction of their linear elements were done.

\section{Materials and Methods}

In the frames of the present research the following data were used: topographic maps of HGMS of scale 1:50,000, geological maps of IGME of scale 1:50,000, satellite images, (11-8-84 LANDSAT 5 TM BAND:4 TRACK:184 FRAME:032 Q:3 and 11-8-84 LANDSAT 5 TM BAND:5 TRACK:184 FRAME:033 Q:1), bibliographic data and field work.

The topographic and geological maps were scanned and then georeferenced to the Greek Geodetic Reference System (GGRS 87), by using the ArcGIS ver. 9.0 software. The contour lines at $20 \mathrm{~m}$ intervals, the hypsometric points, the drainage network, as well as the watershed were obtained from the topographic maps and were manually digitized. A DEM of the study area was created using the contour map and the capabilities of the 3D Analyst extension. Then the DEM was converted to a slope map. In the frames of the study of the morphometric settings of drainage network, a classification and ordering of all channels by using the Strahler method (1957) were ac accomplished. Then the $1^{\text {st }}$ and $2^{\text {nd }}$ law of Horton was applied and the density and the frequency of the drainage network were calculated. 
The analysis of geological background and tectonic structures (thrusts, overthrusts, faults) was based on the geological maps of IGME. Moreover, for the analysis and completion of the faults, the bibliographic data (Migiros et al., 1989; Caputo, 1990), the field observations and the lineaments, which were recognized by the satellite images, were used. The statistical analysis of rose diagrams directions and lengths of tectonic lines, watershed and channels of drainage network became with the ROCKWORKS 2004 software.

\section{Geological settings}

The drainage basin of Kleinovitikos stream is structured by Alpine rocks and post-Alpine formations.

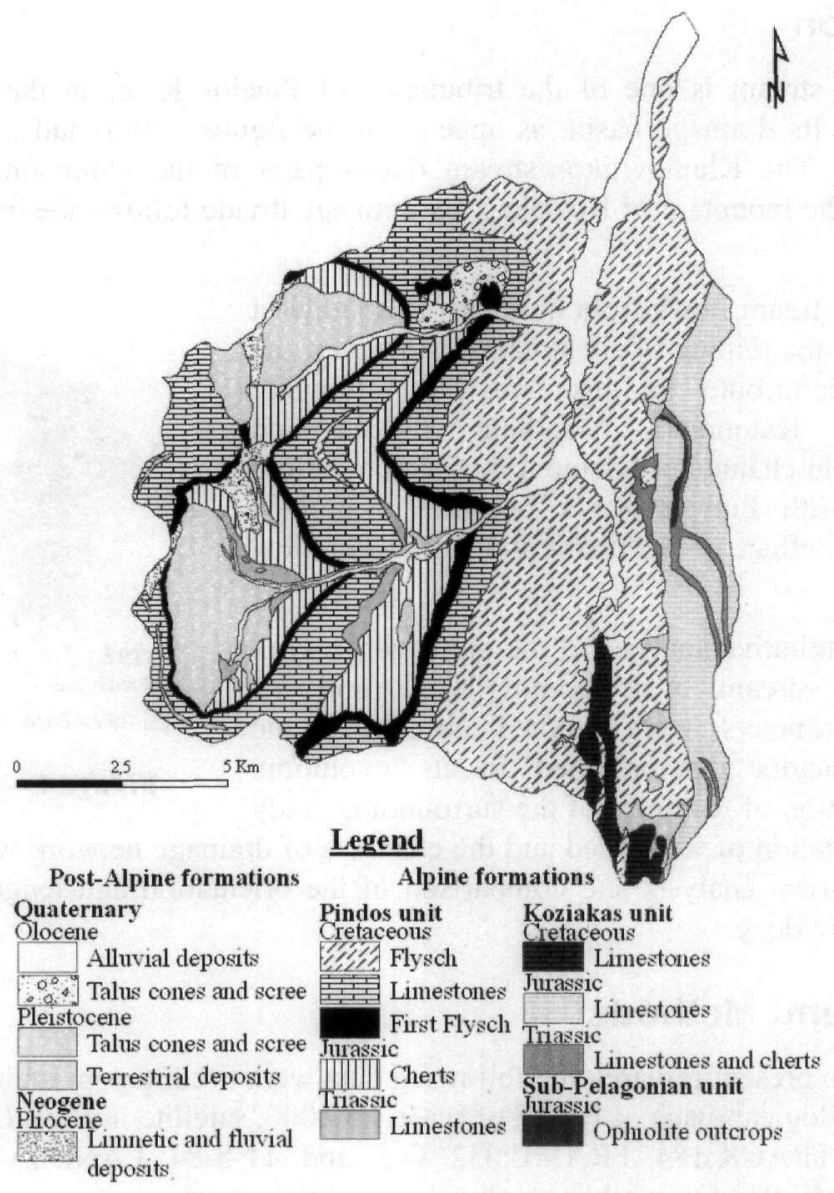

Figure 2 - The lithological formations of the study area

The Alpine background is constituted by limestones, cherts, and flysch of the unit of Pindos, limestones and limestones with cherts of unit of Koziaka as well as ophiolite outcrops of the unit of Sub-Pelagonian. The post Alpine formations are constituted by Pliocene limnic and fluvial deposits, Pleistocene deposits, talus cones and scree, recent coarse-grained relaxed depositions of streams and mantle of weathering (Aubouin 1961, Savoyat and Lalechos 1972). The lithological formations of the study area are showed in the figure 2 .

The stratigraphic units are thrusted on each other, the Pindos Unit being the lower and the SubPelagonian being the upper. The tectonic discontinuities belong to groups of directions of tectonic 
lines, which traverse the area, regardless of the petrographical composition of the geological formations.

\section{Results}

\subsection{Morphological settings of the drainage basin}

The basin of Kleinovitikos stream drainages the hillsides of the Koztaka and the Southern Pindos. The shape of the basin is oblong, while the direction of the big axis is NNA - SSE. Its total area amounts in $173 \mathrm{~km}^{2}$ and the length of its perimeter is $67 \mathrm{~km}$. The drainage basin is particularly mountainous with absolute altitudes ranging from 264 to $2,200 \mathrm{~m}$, while the medium altitude reaches $1,038 \mathrm{~m}$.

The morphological slopes of the basin present various fluctuations (Fig. 3), with mean slope equal to $24.47^{\circ}$. The slopes were categorized in the following five categories: $0^{\circ}-10^{\circ}$ (very gentle slope), $10^{\circ}-20^{\circ}$ (gentle slope), $20^{\circ}$ $30^{\circ}$ (moderate slope), $30^{\circ}-40^{\circ}$ (steep slope), > $40^{\circ}$ (very steep slope).

The gentle slopes $\left(0^{\circ}-10^{\circ}\right.$ and $\left.10^{\circ}-20^{\circ}\right)$ are distributed in the entire basin and mainly in its central part. These are represented mainly in the valley wall of the bed of the main channel of Kleinovitikos stream and in beds of its tributaries. Besides the moderate slopes are presented in the entire area but mainly are observed in the mountainous regions of Pindos and Koziakas in the western and eastern parts of the basin. These slopes characterize more erosional landforms than geological and tectonic structures. Finally, in the western and

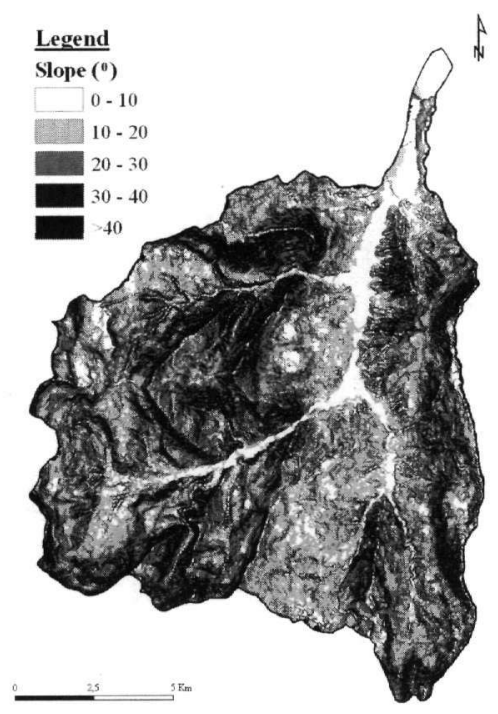

Figure 3 - The slopes of the drainage basin eastern part of the basin and mainly along the orographic axes of mountain ranges of Pindos and Koziakas very steep slopes with high cliffs are observed. Moreover, in the areas where the geological background is composed of the formations of units of Pindos and Koziakas, the layers present very high slopes and they are almost vertical. The very steep slopes represent geological and tectonic structures.

\subsection{Morphometric settings of the drainage network}

The statistical analysis showed that the main channel of the drainage network is of 6th order in (Fig. 4). The drainage network comprises 1085 channels, of a total length $623 \mathrm{~km}$.

The type of the drainage network of Kleinovitikos stream is complex. Dominating form is the trellis drainage pattern, in southern-southwestern and in the northern part of the drainage system. In its western part has a dendritic drainage pattern. The tectonic of the area and the erosion process resulted in the trellis drainage network of Kleinovitikos stream. The complex network of Kleinovitikos stream proves the complicated geological and tectonic structure, as well as the complex geomorphology of the area.

\subsubsection{The first law of Horton}

The results of the application of $1^{\text {st }}$ law of Horton in the drainage network of Kleinovitikos stream. are shown in table 1. 
The negative deviation values show that the number of channels in each order is less than the expected ones. The higher deviation value is observed in the streams of $5^{\text {th }}$ order. The streams of $4^{\text {th }}$ order are joined straight with the stream of $6^{\text {th }}$ order so that are not created streams of $5^{\text {th }}$ order. This make is also confirmed by the high value of bifurcation ratio $(R b=5)$ of the streams of $5^{\text {th }}$ order. The tectonic structure of the area probably affects the growth of number of the streams of the drainage network. Moreover, the trellis network of Kleinovitikos stream due in the tectonic activity.

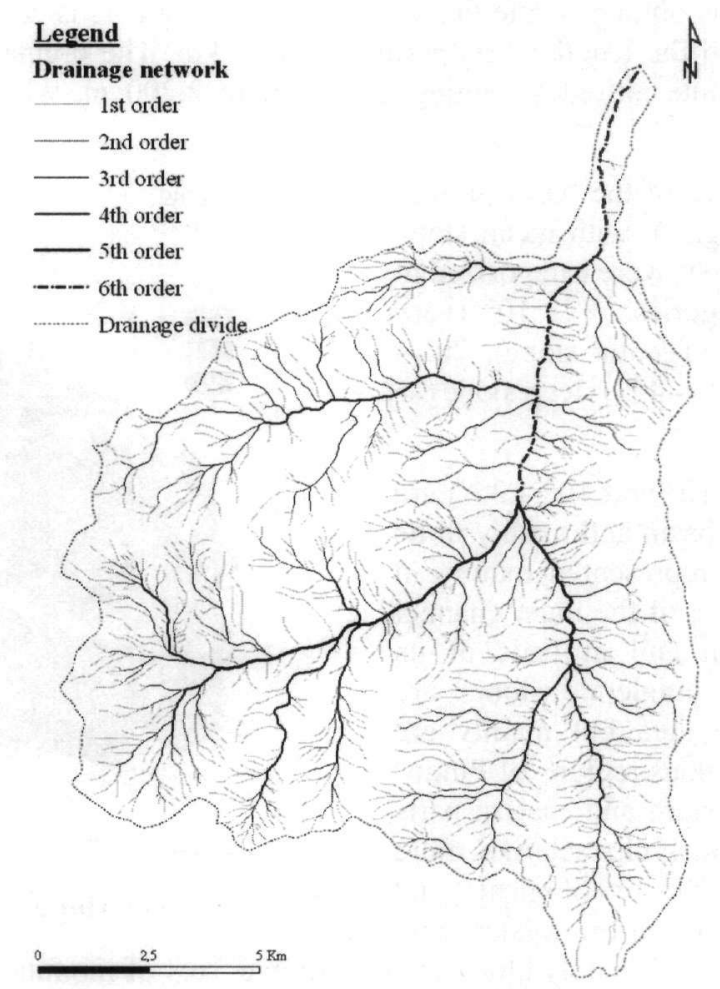

Figure 4 - The drainage network of Kleinovitikos stream

The bifurcation ratio $(\mathrm{Rb})$ of the drainage basin of Kleinovitikos stream is high and equal to 4.01. According to Horton (1945), the ideal value is 2, while the values from 2 up to 5 show a well developed drainage network (Leopold et al. 1995, Alexouli - Livaditi 1999).

Table 1 - Bifurcation characteristics of the drainage network

\begin{tabular}{|l|l|l|l|l|l|}
\hline $\begin{array}{c}\text { Order } \\
\mathbf{u}\end{array}$ & $\begin{array}{c}\text { Number of } \\
\text { streams Nu }\end{array}$ & $\begin{array}{c}\text { Bifurcation } \\
\text { ratio Rb }\end{array}$ & $\begin{array}{c}\text { Average } \\
\text { bifurcation ratio }\end{array}$ & $\begin{array}{c}\text { Ideal number } \\
\text { of streams }\end{array}$ & $\begin{array}{c}\text { Deviation } \\
(\%)\end{array}$ \\
\hline 1 & 817 & & & 1038 & -21.27 \\
\hline 2 & 208 & 3.93 & & 259 & -19.61 \\
\hline 3 & 47 & 4.43 & 4.01 & 65 & -27.15 \\
\hline 4 & 10 & 4.70 & & 16 & -37.83 \\
\hline 5 & 2 & 5.00 & & 4 & -50.13 \\
\hline 6 & 1 & 2.00 & & 1 & 0.00 \\
\hline
\end{tabular}




\subsubsection{The second law of Horton}

In table 2 are shown the results of application of $2^{\text {nd }}$ law of Horton drainage network of the study area.

In the streams of all orders of the drainage network are observed negative deviation values with the higher value in the stream of $2^{\text {nd }}$ order. The negative deviation values in all the streams show that in the drainage basin is encouraged the percolation against the surface flow. Due to the fact that the study area is characterized by high variety of rocks and sediments, this heterogeneity affects immediately, the appearance of small lengths of streams. Moreover the tectonic activity appears to affect promptly also, the increase of the stream length.

The deviations which were detected by the application of the laws of Horton indicate that the drainage network of Kleinovitikos stream seems to be in a youth or an advanced youth stage of evolution. This fact may have been resulted by the recent uplift movement of Koziakas mountain (Migiros et al., 1989), so the drainage network that is still developed, has not been adapted in the new condition.

Table 2 -Number and length of the drainage network

\begin{tabular}{|l|l|l|l|l|l|l|}
\hline $\begin{array}{c}\text { Order } \\
(\mathbf{u})\end{array}$ & $\begin{array}{c}\text { Length of } \\
\text { streams } \mathbf{L}_{\mathbf{u}} \\
(\mathbf{K m})\end{array}$ & $\begin{array}{c}\text { Mean length } \\
\mathbf{L}_{\mathbf{u}}(\mathbf{K m})\end{array}$ & $\begin{array}{c}\text { Length ratio } \\
\mathbf{L}_{\mathbf{u}} / \mathbf{L}_{\mathbf{u}-\mathbf{1}}\end{array}$ & $\begin{array}{c}\text { Average } \\
\text { length } \\
\text { ratio }\end{array}$ & $\begin{array}{c}\text { Mean ideal } \\
\text { length of } \\
\text { streams }\end{array}$ & $\begin{array}{c}\text { Deviation } \\
(\%)\end{array}$ \\
\hline 1 & 387 & 0.47 & & & 0.47 & 0.00 \\
\hline 2 & 123.5 & 0.59 & 1.25 & & 0.91 & -35.04 \\
\hline 3 & 57 & 1.21 & 2.04 & 1.93 & 1.76 & -31.23 \\
\hline 4 & 32 & 3.20 & 2.64 & & 3.40 & -5.96 \\
\hline 5 & 12.5 & 6.25 & 1.95 & & 6.57 & -4.82 \\
\hline 6 & 11 & 11.00 & 1.76 & & 12.67 & -13.18 \\
\hline
\end{tabular}

\subsubsection{The drainage density and frequency}

The drainage density of the basin is $3.612 \mathrm{~km} / \mathrm{km}^{2}$ and the drainage frequency has been estimated to be 6,285 channels $/ \mathrm{km}^{2}$. The values of drainage density and frequency are lower compared with the corresponding values (Bathrellos et al. 2005) that have been observed in neighboring drainage basins.

The hydrologic characteristics of the formations of the basin control the drainage density and frequency (Leopold et al. 1995). Because of this the geological formations were categorized based on their hydrologic characteristics in three categories: permeable, semi-permeable and impermeable formations. The permeable and impermeable formations cover the same area, which is equal to $85 \mathrm{~km}^{2}$ for each category and correspond the $49 \%$ of the entire area. The semipermeable formations have very small appearance, with extent equal to $3 \mathrm{~km}^{2}$, while they possess the $2 \%$, of the total area (Bathrellos 2005).

The presence of alternating lithological formations (Fig. 2) affects in the values of drainage density and frequency of the basin. The developing lithological discontinuities prevent the elongation of streams, as well as the increase of their number.

In addition, another factor, which acts on the drainage density and frequency values, is the vegetation of hill slopes. The heavy vegetation of the study area is represented mainly by extensive forests; it has as consequence the percolation increase against the surface flow. 


\subsection{The relation of the tectonic with the drainage network}

The tectonic structure of the area has affected and it continues affecting the evolution of the slopes, as well as the shape of the main drainage divide and the drainage network. Aiming at the investigation of the relationship of the tectonics with the channels of the drainage network as well as the watershed of the study area, the thrusts, overthrusts and the lineaments of surrounding area were analyzed.

As it is resulted from the rose diagram of frequency of the figure 5 the overthrusts and thusts have the following main, secondary and tertiary directions:

Main direction: $160^{\circ}-170^{\circ}$, secondary directions: $80^{\circ}-110^{\circ}, 140^{\circ}-160^{\circ}, 170^{\circ}-180^{\circ}$, tertiary directions (or directions of very low frequency): $0^{\circ}-20^{\circ}$ and $110^{\circ}-140^{\circ}$.

The statistical analysis of the density of the overthrusts and thrusts is shown in the second rose diagram of the figure 5. In all directions of the overthrusts and thrusts the density follows the frequency. An exception is the $150^{\circ}-160^{\circ}$ direction where it presents higher density than frequency.

A

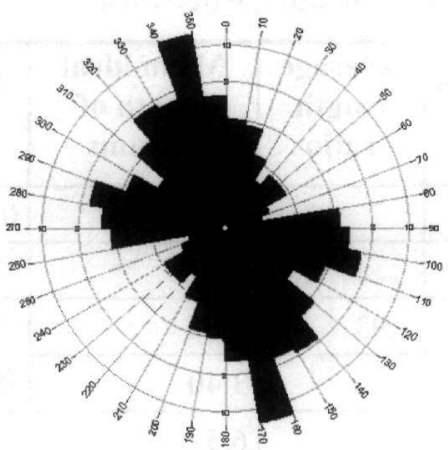

B

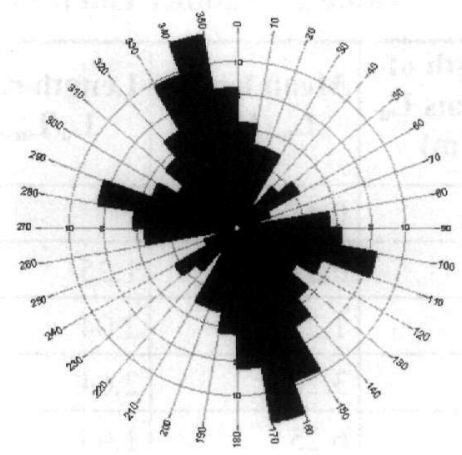

Figure 5 - Rose diagrams of frequency (A) and density (B) for thrusts and overthrusts

The rose diagrams of frequency and density for lineaments of the study area is given in the figure 6. Lineaments follow the following main, secondary and low directions: main direction: $40^{\circ}-60^{\circ}$, secondary directions: $0^{\circ}-10^{\circ}, 30^{\circ}-40^{\circ}, 140^{\circ}-170^{\circ}$, tertiary directions: $90^{\circ}-100^{\circ}$.

A

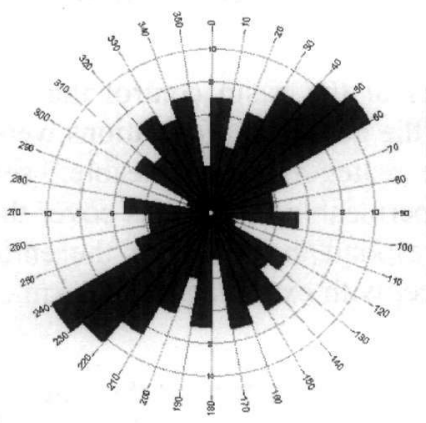

B

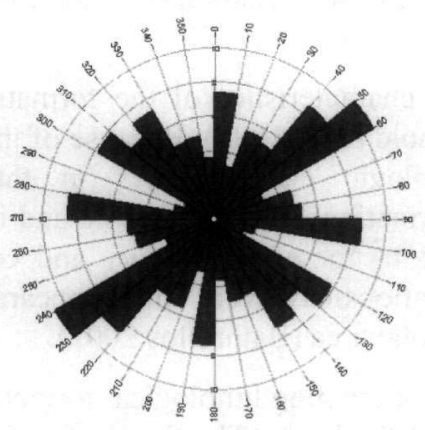

(A) and density (B) for faults

According the rose diagram of density for fault system (Fig. 6), is realized that the directions of density are different from the frequency ones. The prevailing directions of lengths are: main direction: $50^{\circ}-60^{\circ}$, secondary direction: $0^{\circ}-10^{\circ}, 40^{\circ}-50^{\circ}, 90^{\circ}-100^{\circ}, 120^{\circ}-150$. 
A

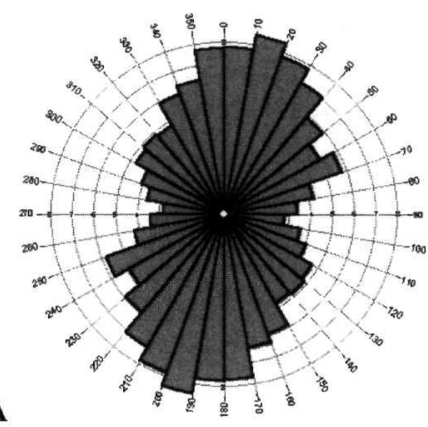

B

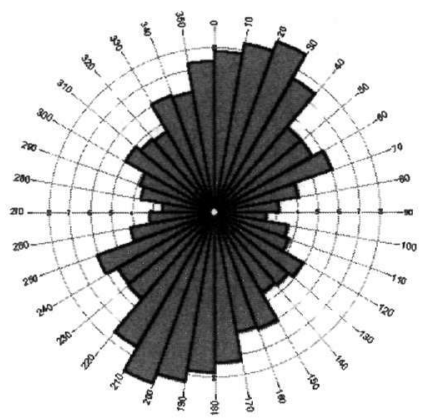

Figure 7 - Rose diagrams of frequency (A) and density (B) for the watershed

Then, the watershed of Kleinovitikos stream was analyzed statistically. The rose diagrams of frequency and density for the watershed are presented in the figure 7 . The directions of frequency are: main direction: $350^{\circ}-40^{\circ}$, secondary directions: $40^{\circ}-50^{\circ}, 60^{\circ}-70^{\circ}$ and $150^{\circ}-170^{\circ}$. The main direction of density follows the frequency $\left(350^{\circ}-40^{\circ}\right)$. Secondary directions of density are: $60^{\circ}-70^{\circ}$ and $150^{\circ}-170^{\circ}$.

The rose diagramms of frequency and density for the streams of the drainage network of Klenovitikos stream are shown in figures 8 to 14 . The main direction of frequency and density for all the streams of drainage network is $80^{\circ}-100^{\circ}$. The main and secondary directions for the streams of each order are described in Table 3.

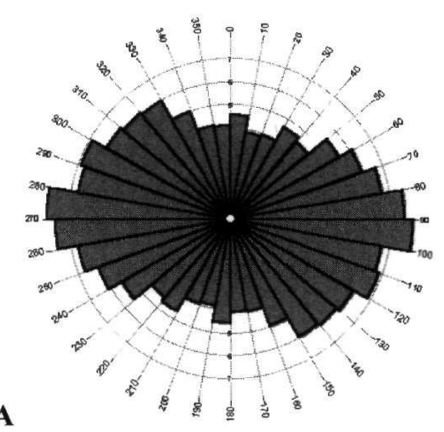

A

\section{Figure 8 - Rose diagrams of frequency (A) and density (B) for all the streams}

From the rose diagrams of figure 5 and 6 it is clear that the locality of tectonic structures is influenced by the $\mathrm{E}-\mathrm{W}$ direction. These faults substantially cut all the preexisting important tectonic structures.

Comparing the rose diagrams of the watershed of Kleinovitikos stream (Fig. 7) with those of tectonic lines (Figs 5,6) we conclude that the watershed presents main direction of frequency $10^{\circ}$ $-30^{\circ}$. The predominance of this direction is controlled from the lithology and the secondary cracks.

The directions of rose diagrams of the entire streams and streams of $1^{\text {st }}-3^{\text {rd }}$ order of Kleinovitikos stream basin present directions which show the influence of neotectonic cracks (Figs 9 to 11). As the streams of these orders are younger, are probably related more with the earlier fractures, such as $\mathrm{E}-\mathrm{W}$ direction faults. 
Table 3 - Directions of frequency and density for the streams of each order.

\begin{tabular}{|l|l|l|l|l|}
\hline Order & \multicolumn{1}{|c|}{ Frequency } & \multicolumn{1}{c|}{ Density } & \multicolumn{1}{c|}{ Frequency } & \multicolumn{1}{c|}{ Density } \\
\hline & Main directions & Secondary directions & Main directions & Secondary directions \\
\hline 1st & $80^{\circ}-100^{\circ}$ & $100^{\circ}-120^{\circ}$ & $80^{\circ}-100^{\circ}$ & $100^{\circ}-120^{\circ}$ \\
\hline 2nd & $70^{\circ}-100^{\circ}$, & $100^{\circ}-130^{\circ}$, & $70^{\circ}-100^{\circ}$, & $100^{\circ}-120^{\circ}$, \\
& $130^{\circ}-140^{\circ}$ & $140^{\circ}-150^{\circ}$ & $120^{\circ}-140^{\circ}$ & $140^{\circ}-150^{\circ}$ \\
\hline 3rd & $60^{\circ}-70^{\circ}$, & $80^{\circ}-90^{\circ}$, & $60^{\circ}-70^{\circ}$, & $80^{\circ}-90^{\circ}$, \\
& $90^{\circ}-100^{\circ}$ & $100^{\circ}-110^{\circ}$ & $90^{\circ}-100^{\circ}$ & $100^{\circ}-110^{\circ}$ \\
\hline 4 th & $0^{\circ}-20^{\circ}$, & $20^{\circ}-30^{\circ}$ & $0^{\circ}-10^{\circ}$ & $10^{\circ}-30^{\circ}, 90^{\circ}-110^{\circ}$ \\
\hline 5th & $90^{\circ}-110^{\circ}$ & & & $60^{\circ}-70^{\circ}$ \\
\hline 6th & $60^{\circ}-80^{\circ}$ & $30^{\circ}-40^{\circ}, 50^{\circ}-60^{\circ}$ & $70^{\circ}-80^{\circ}$ & $10^{\circ}-30^{\circ}$ \\
\hline
\end{tabular}

A

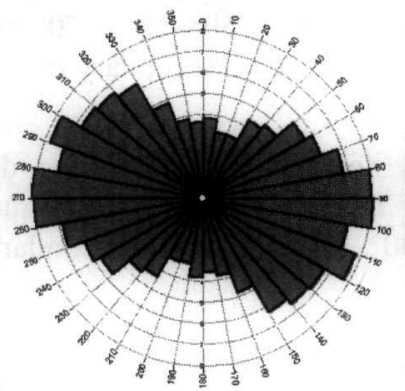

B

Figure 9 - Rose diagrams of frequency (A) and density (B) for $1^{\text {st }}$ order streams

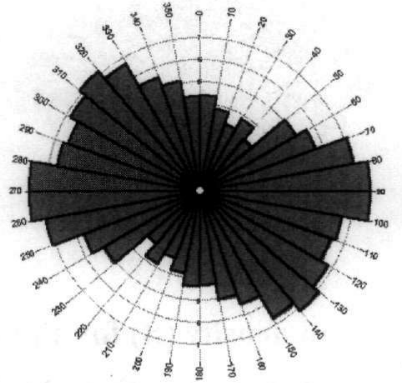

A

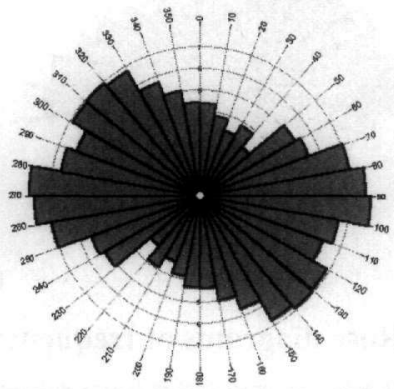

Figure 10 - Rose diagrams of frequency (A) and density (B) for $2^{\text {nd }}$ order streams

The streams of $4^{\text {th }}$ and $5^{\text {th }}$ order present directions that are influenced by younger cracks and older Alpine cracks (Figs 12, 13).

The stream of $6^{\text {th }}$ order of the drainage network presents directions in which the effect of older Alpine cracks is obvious (Fig. 14). 

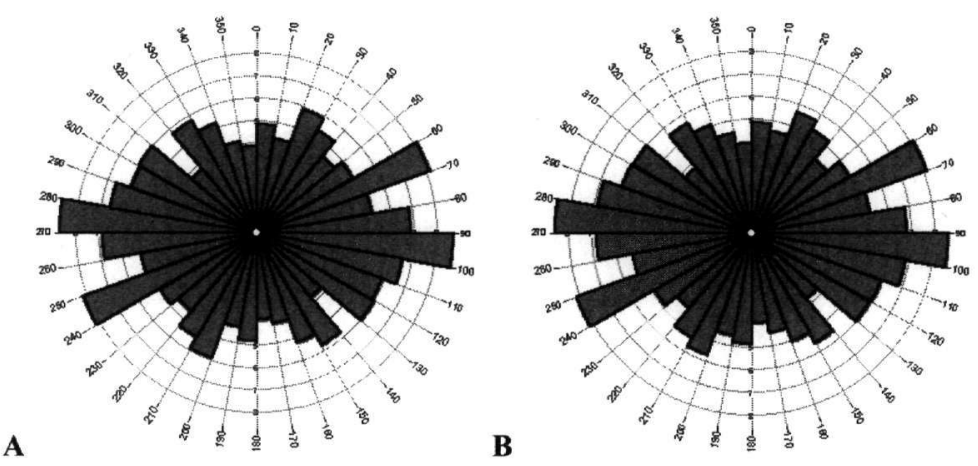

Figure 11 - Rose diagrams of frequency (A) and density (B) for $3^{\text {rd }}$ order streams

A

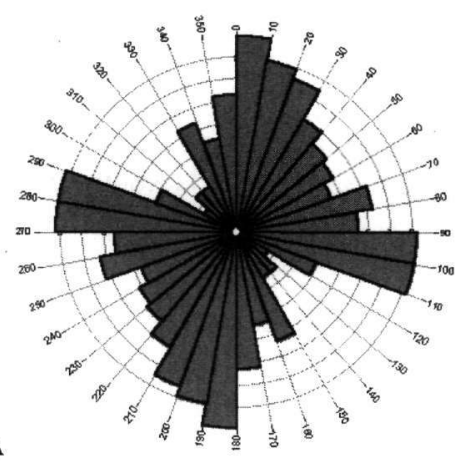

B

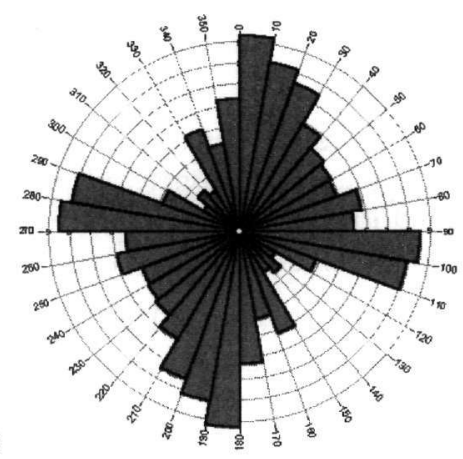

Figure 12 - Rose diagrams of frequency (A) and density (B) for $4^{\text {th }}$ order streams

A

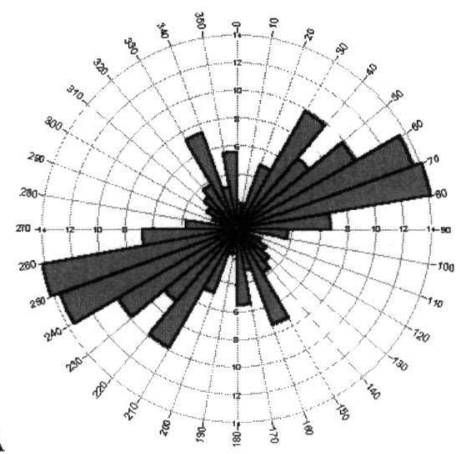

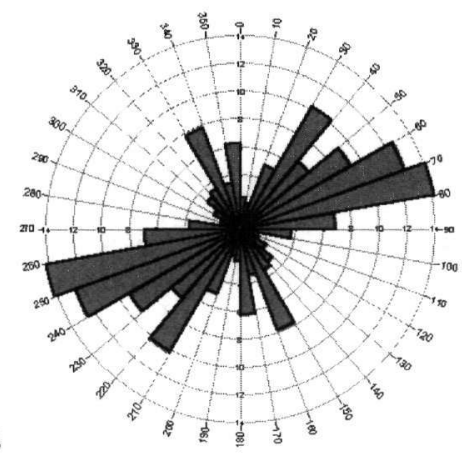

B

Figure 13 - Rose diagrams of frequency (A) and density (B) for $5^{\text {th }}$ order streams

\section{Conclusions}

The Kleinovitikos stream basin drainages the hillsides of the Kozlaka mountain and the Southern Pindos mountain range. The shape of the drainage basin is oblong, and its axis has NNE - SSW direction.

The morphological slopes present various fluctuations, while the mean slope is $24.47^{\circ}$. The gentle slopes are distributed in the entire basin. The moderate slopes are mainly observed in the mountainous regions of Pindos and Koziakas, in the western and eastern parts of the basin. These slopes express more erosional landforms than geological and tectonic structures. The steep slopes 

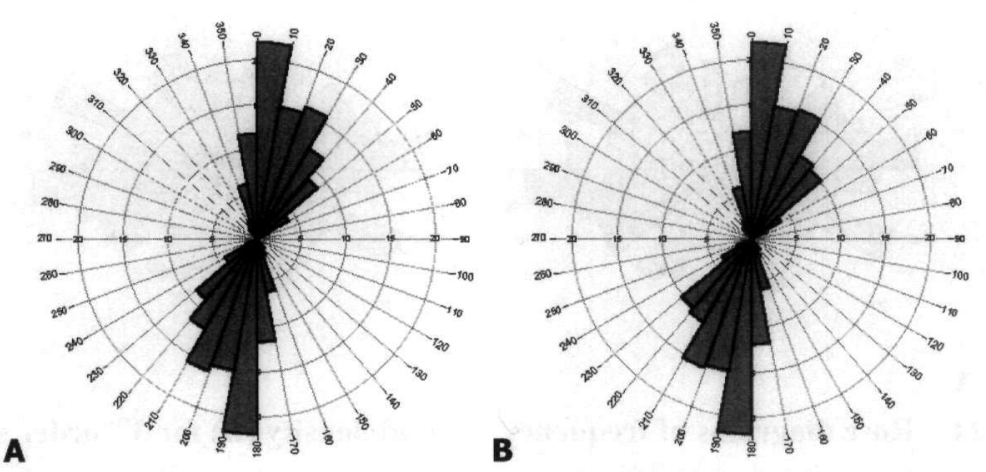

Figure 14 - Rose diagrams of frequency $(A)$ and density (B) for $6^{\text {th }}$ order stream

are distributed mainly along of orographic axes of Pindos and Koziakas and represent geological and tectonic structures.

The statistical analysis revealed that the main channel of the drainage network is of $6^{\text {th }}$ order. The dominating type of the drainage network is the trellis pattern, in its southern-southwestern and northern part. Dendritic drainage network was noted in its western part. The tectonic activity and the erosion affect the trellis drainage pattern of Kleinovitikos stream.

The application of the first law of Horton showed that the steams of all orders of the drainage network present negative deviation values from the ideal ones. The higher deviation value was defined in the stream of $5^{\text {th }}$ order. The tectonic structure of the area probably affects the number of the streams of the drainage network. In addition, the application of the second law of Horton showed negative deviation values in the streams of all orders of the drainage network. The higher value was observed in the streams of $2^{\text {nd }}$ order. The outcrop of alternating lithological formations in the drainage basin as well as the tectonic activity affect promptly in the increase of the stream length. The deviations which observed by the application of the laws of Horton indicate that the drainage network of Kleinovitikos stream appears to be in the youth or advanced youth of evolution. Cause of this is the recent uplift movement of Koziakas mountain, so the drainage network that is still developing, it has not been adapted in the new condition.

The drainage basin is covered by equal percentages of permeable and impermeable formations. This fact has a direct effect in the values of drainage density and frequency. The developing lithological discontinuities prevent the elongation of streams, as well as the growth of their number. Besides the vegetation of slopes has as consequence the percolation increase against the surface flow.

The correlation of tectonic characteristics, watershed and channels of the drainage network indicate that:

- Lithology as well as the secondary cracks affect the prevailing direction of the watershed.

- The streams of $1^{\text {st }}$ to $3^{\text {rd }}$ order of the drainage network are controlled from younger cracks.

- The streams of $4^{\text {th }}$ and $5^{\text {th }}$ order are influenced by younger cracks and older Alpine cracks.

- The Alpine tectonic activity controls the stream of $6^{\text {th }}$ order.

\section{References}

Alexouli-Livaditi, A., 1999. Quantitative geomorphological study of Eurotas river drainage network (Greece), Proc. of the $5^{\text {th }}$ Geographic Congress, Athens, 11-13 November, 206-216. 
Aubouin, J., 1961. Geological map, Pramanta sheet, scale 1:50,000, IGME publications.

Bathrellos, G., 2005. Geological geomorphological and geographic study of urban areas in Trikala prefecture - Western Thessaly, PHD Thesis, National and Kapodistrian University of Athens, Greece, 567pp.

Bathrellos, G., Skilodimou, H., Livaditis, G., and Verikiou-Papaspiridakou, E., 2005. Geomorphological and morphotectonic analysis of Malakasiotis drainage basin, Bull. of Geological Society of Greece, XXXVIII, 123-133.

Caputo, R., 1990. Geological and structural study of the recent and active brittle deformation of the Neocene-Quaternary basins of Thessaly (Central Greece), PHD Thesis, Aristotelion University of Thessaloniki, 252pp.

Horton, R., 1945. Erosional development of streams and drainage basins: hypsographical aproach to quantitative morphology, Bull. of Geological Society of America, 54, 275-370.

Leopond, L., Wolmam, M.G., and Miller, J., 1995. Fluvial Processes in Geomorphology, New York, Dover Publications, INC., 522pp.

Migiros, G., Manakos, K., Skourtsis-Coroneou, V., and Karfakis, I., 1989. The Geological structure of Koziakas region (W. Thessaly, Greece), Bull. of Geological Society of Greece, XXIII/1, 381-393.

Savoyat, E., and Lalechos N., 1972. Geological map, Kalampaka sheet, scale 1:50,000, IGME publications.

Strahler, A.N., 1957. Quantitative analysis of watershed geomorphology, Am. Geophys. Union Trans., 38(6), 913-920. 